\section{Gender differences in self-reported morbidity: evidence from a population-based study in southern Brazil}

\author{
Diferenças na morbidade referida entre sexos: \\ evidências de um estudo de base populacional \\ no Sul do Brasil
}

\footnotetext{
${ }^{1}$ Departamento de Medicina Interna, Fundação Universidade Federal do Rio Grande, Rio Grande, Brasil. 2 Pós-graduação em Saúde Coletiva, Universidade Luterana do Brasil, Canoas, Brasil.

Correspondence R. A. Mendoza-Sassi Departamento de Medicina Interna Fundação Universidade Federal do Rio Grande. Rua Dr. Pedro A. Gatti 99, Rio Grande, RS 96216-080, Brasil. rmend@vetorial.net dmiraul@furg.br
}

\begin{abstract}
This paper aims to assess variations in self-reported morbidity between men and women using six different measures of reported illness. The cross-sectional study was conducted in the municipality of Rio Grande, southern Brazil. Demographic, socioeconomic, and morbidity data were collected from a probabilistic sample of 1,260 persons aged 15 years or over, using a specific questionnaire. Statistical analysis included a multivariate Poisson regression analysis. Prevalence Ratios (PR) with 95\% confidence intervals (95\%CI) were calculated. After adjusting for some confounding variables (age, race, unemployment, marital status, income, social class, and education), women showed greater risk of any symptom $(P R=3.21 ; 95 \% C I$ : 2.71-3.83), three or more symptoms ( $P R=4.22$; 95\%CI: 2.97-5.98), potentially serious symptoms $(P R=1.75 ; 95 \% C I: 1.31-2.34)$, poor/fair health $(P R=1.78 ; 95 \% C I: 1.37-2.32)$, and minor psychiatric disorders ( $P R=1.76$; 95\%CI: 1.31-2.37). The study revealed dissimilarity in self-reported morbidity between men and women in southern Brazil, but with different degrees depending on type of morbidity. This excess can be explained by gender difference in health-seeking behavior for perceiving or reporting health problems.
\end{abstract}

Gender; Patient Acceptance of Health Care; Morbidity
Raúl A. Mendoza-Sassi 1

Jorge U. Béria 2

\section{Introduction}

It is well known that although men have higher rates of mortality, women report and have more morbidity than men. Some theories have attempted to identify the reasons for this higher morbidity rate among women. There are two broad theories: (1) biological, contending that most of the problem is related to hormonal and genetic differences between men and women (menstruation and menopause, for example) and (2) psychosocial, according to which the difference is due mainly to women's role in society and their behavior towards illness 1,2 .

This dissimilarity can vary among countries 3,4 and a unique global pattern should not be expected. Health differences between men and women in Brazil have been well established for mortality 5 and health services utilization 6,7. There is much less information on morbidity. One of the few studies on this matter, using data from the National Household Sample Survey (PNAD 1998), showed that women had more chronic disease and worse self-reported health, which changed with age 8 .

Most studies assessing gender differences in morbidity fail to take into account that other factors (e.g., socioeconomic and demographic) can affect outcome. Evidence exists that self-reported health can be affected by education, even between countries 3 , and marital status 9 . Thus, assessing the real effect of gender on morbidity 
requires adjusting the models for these potential confounders.

Another relevant aspect is that there are various types of morbidity to be studied. Morbidity can be analyzed using medical records or selfreported data. Self-reported morbidity can range from symptoms, chronic health conditions, and health perception to number of inactive days 10 , but each assesses a specific condition. Thus, differences in morbidity between men and women may change according to the definition.

This study thus aimed to assess the variation in self-reported morbidity between men and women in southern Brazil according to six different measures considering economic and demographic factors and to elucidate health-seeking behavior in Brazil.

\section{Methods}

The study was cross-sectional, conducted in the municipality of Rio Grande, southern Brazil, from January to May 2000. The sample need to detect a 1.5 relative risk with $80 \%$ power, $95 \%$ confidence level, 1:1 ratio of exposed/unexposed, and prevalence of $16 \%$ for poor/fair self-reported health in the unexposed group (men) was 832 subjects. This figure was increased by $50 \%$ for losses, confounding control, and design effect, thus totaling 1,248 .

The sampling used a multistage random method. In the first stage, 45 of 242 census tracts in the municipality were selected. In the second stage a block was randomly selected, and in each block one of the corners was chosen. In the third stage, starting from each corner, one of every three houses was systematically visited, totaling 12 households in each sampled block.

All household members 15 years or older were interviewed using a questionnaire with socioeconomic (social class, income, education, race, unemployment), demographic (age, gender, marital status), and self-reported morbidity items. When measuring morbidity in a population-based setting, one condition is the collection of satisfactory data. As some studies have shown, self-reported morbidity is an adequate way to evaluate health condition and is well related with mortality 11,12 . In this study we employed six different measures of self-reported morbidity, attempting to widen the spectrum of disease experience and assess different health situations: (a) presence of a symptom in the previous two months using a list of $18 \mathrm{com}$ mon symptoms ("vaginal bleeding" was not included in the analysis in an attempt to minimize the effect of this particular and common condition on gender differences); (b) three or more symptoms; (c) potentially serious symptoms, characterized by shortness of breath or blood in urine or stool in the two months prior to the interview; (d) chronic health problems, assessed by asking whether the physician had informed the person that he/she had a chronic health problem; (e) self-reported health status, addressed by the question "How has your health been in the last 12 months?" and rated as poor, fair, good, or excellent. For analytical purposes, the latter was transformed into a dichotomous variable, where "poor" was combined with "fair" and "good" with "excellent"; (f) minor psychiatric disorders (MPD), assessed by the Self-Report Questionnaire-20 validated in Brazil 13. A 5/6 cut-off was used for men and 7/8 for women.

Demographic and socioeconomic data were obtained, and questions were asked on age, race, marital status, social class, unemployment, income, and education. Race was classified as white or non-white. Education was measured as years of schooling attainment. Income was collected for all family members, and per capita family income was calculated. Social class was categorized according to the Brazilian Market Research Association (ABIPEME) criteria in five decreasing categories A, B, C, D, and E. Each family was categorized according to head-of-family's schooling and types of households appliances 14 . For analytical purposes, class A was combined with class $\mathrm{B}$, and class $\mathrm{E}$ with $\mathrm{D}$.

Statistical analysis used Stata 6.0 for Windows (Stata Corporation, College Station, USA). A 0.05 cutoff point was set for the $\mathrm{p}$-value and applied in all statistical analysis. Crude prevalence ratios (PR) and 95\% confidence intervals (95\%CI) were calculated between gender and each of the morbidity variables in the bivariate analysis. A forward stepwise Poisson regression was used in the multivariate analysis. PR and 95\%CI were obtained between morbidity and gender, adjusted to demographic and socioeconomic variables. Six different models were constructed, one for each morbidity group. Wald test was used to assess the models' significance. Robust variance estimates were obtained, taking into account the possibility of non-independent observations in each cluster (census tracts)

\section{Results}

Some 1,260 persons from 540 households were interviewed. Table 1 shows the frequencies of the study variables. Classes A and B comprised $27 \%$, class C $40 \%$, and classes D and E $33 \%$ of the sample. There was a slight majority of women 
Characteristics of the study sample. Rio Grande, Rio Grande do Sul, Brazil ( $n=1,260)$.

\begin{tabular}{|c|c|c|}
\hline Variables & $\%$ & $\mathrm{n}$ \\
\hline \multicolumn{3}{|l|}{ Social class * $(n=1,258)$} \\
\hline$A / B$ & 26.9 & 338 \\
\hline C & 39.6 & 499 \\
\hline $\mathrm{D} / \mathrm{E}$ & 33.5 & 421 \\
\hline Unemployment previous month & 8.9 & 112 \\
\hline \multicolumn{3}{|l|}{ Schooling (years) } \\
\hline$\leq 3$ & 21.2 & 267 \\
\hline $4-7$ & 32.4 & 408 \\
\hline $8-10$ & 21.1 & 266 \\
\hline$\geq 11$ & 25.3 & 318 \\
\hline \multicolumn{3}{|l|}{ Gender } \\
\hline Male & 46.1 & 581 \\
\hline Female & 53.9 & 679 \\
\hline \multicolumn{3}{|l|}{ Age group (years) } \\
\hline $15-24$ & 23.9 & 301 \\
\hline $25-44$ & 37.1 & 467 \\
\hline $45-64$ & 27.8 & 351 \\
\hline$\geq 65$ & 11.2 & 141 \\
\hline \multicolumn{3}{|l|}{ Race } \\
\hline White & 84.7 & 1,067 \\
\hline Non-white & 15.3 & 193 \\
\hline Symptom previous 2 months & 62.7 & 790 \\
\hline$\geq 3$ symptoms & 42.9 & 540 \\
\hline Potentially serious symptoms & 16.8 & 211 \\
\hline Chronic health problems & 25.4 & 320 \\
\hline \multicolumn{3}{|l|}{ Self-reported health (previous year) } \\
\hline Good/Excellent & 74.4 & 937 \\
\hline Poor/Fair & 25.6 & 323 \\
\hline \multicolumn{3}{|l|}{ Minor psychiatric disorders } \\
\hline Male & 12.7 & 74 \\
\hline Female & 22.1 & 150 \\
\hline
\end{tabular}

* ABIPEME 14 .

(53.9\%). Mean age was 40.33 years (SD 17.71) and ranged from 15 to 94 .

An important proportion of subjects had experienced at least one symptom in the previous two months $(62 \%)$, and nearly $17 \%$ had a potentially serious symptom in the same period. Onefourth reported a chronic health problem, and one-fifth rated their health as poor or fair in the previous year. Women had more minor psychiatric disorders than men $(22.1 \%$ vs. $12.7 \%)$, and overall prevalence of this condition was $17.9 \%$.

Table 2 shows crude PR of self-reported morbidity according to gender. In all of the situations women had a higher risk, although the magnitude was different and varied according to the type of morbidity in question. For "having any symptom" and " 3 or more symptoms", the PRs for women were more than three times higher than for men. All other outcomes had moderate or even low risk measures.

Table 3 shows the adjusted PR and 95\%CI. After adjusting for demographic and socioeconomic variables, few changes can be observed. The most important change was that "chronic health problems" lost significance. All other categories maintained either the same values or ones near the previously observed crude PR.

\section{Discussion}

The paper explored how women and men differ in self-reported morbidity in southern Brazil. As expected, women were more likely to report 
Table 2

Crude prevalence ratios (PR) for morbidity measures according to gender. Rio Grande, Rio Grande do Sul, Brazil ( $n=1,260)$.

\begin{tabular}{|c|c|c|c|c|c|c|}
\hline \multirow[t]{3}{*}{ Morbidity } & \multicolumn{4}{|c|}{ Gender } & \multirow[t]{3}{*}{ PR (95\%Cl) } & \multirow[t]{3}{*}{$\mathbf{P}$} \\
\hline & \multicolumn{2}{|c|}{ Female $(n=679)$} & \multicolumn{2}{|c|}{ Male $(n=581)$} & & \\
\hline & $\%$ & $\mathbf{n}$ & $\%$ & $\mathbf{n}$ & & \\
\hline Any symptom & 90.72 & 627 & 28.05 & 163 & $3.23(2.83-3.69)$ & 0.001 \\
\hline$\geq 3$ symptoms & 65.99 & 448 & 15.83 & 92 & $4.17(3.43-5.06)$ & 0.001 \\
\hline Potentially serious symptoms & 20.50 & 139 & 12.40 & 72 & $1.65(1.27-2.25)$ & 0.001 \\
\hline Chronic health problems & 27.80 & 189 & 22.50 & 131 & $1.23(1.01-1.54)$ & 0.03 \\
\hline \multicolumn{7}{|l|}{ Poor/fair self-reported } \\
\hline health (previous year) & 30.80 & 209 & 19.60 & 114 & $1.71(1.32-2.32)$ & 0.005 \\
\hline Minor psychiatric disorders & 22.20 & 151 & 12.70 & 74 & $1.75(1.32-2.71)$ & 0.001 \\
\hline
\end{tabular}

Table 3

Adjusted prevalence ratio and 95\% confidence interval for gender and morbidity measures. Rio Grande, Rio Grande do Sul, Brazil $(n=1,242)$

\begin{tabular}{|c|c|c|}
\hline & \multicolumn{2}{|c|}{ Gender * } \\
\hline & Male & Female \\
\hline Any symptom (previous 2 months) & 1.00 & 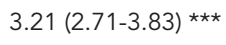 \\
\hline$\geq 3$ symptoms (previous 2 months) & 1.00 & 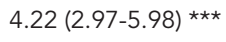 \\
\hline Potentially serious symptoms ** (previous 2 months) & 1.00 & 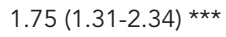 \\
\hline Chronic health problems & 1.00 & $1.14(0.90-1.44) \#$ \\
\hline Poor/fair reported health (previous 2 months) & 1.00 & 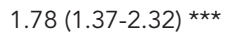 \\
\hline Minor psychiatric disorders & 1.00 & 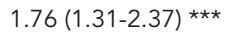 \\
\hline
\end{tabular}

* Adjusted for age, race, unemployment, marital status, social class, income, and education;

$\star \star n=1,241$;

$\star \star \star ~ p=0.001$

$\# p=0.2$.

morbidity than men, and this pattern occurred with almost all types of self-reported morbidity measures used in the study. However, the effect of gender on outcome was not identical for all morbidity groups. For example, for having any symptom or three or more symptoms there was a three or four-fold risk, while for potentially serious symptoms, MPD or self-assessed health perception, the PR did not reach a two-fold increase. For chronic conditions there was no difference.

Some possible constraints may have affected the results and must be analyzed. First, there is the possibility of recall bias. Some morbidity measures were obtained for the previous two months (e.g., symptoms) and others for the previous year (self-reported health perception). It can be argued that this is a long recall period for morbidity, particularly when one explanation for gender differences is that women report symptoms and health problems better than men 15 . If so, and if time acts selectively, reducing men's ability to recall a health problem, the effect may have been overestimated here. Second, although overall losses were only $7 \%$, the proportion of men in the sample was lower than in the losses $(46 \%$ vs. $69 \%, p=0.01$ ). If the men not found at home were working, as usually happens, and which implies healthier status, the effect of female gender on morbidity may have been underestimated. Finally, another potential problem is the lack of power for finding a difference in some outcome variables. This is particularly conceivable for the apparent lack of difference between women and men in chronic health problems. However, the power to find a PR of 1.5 for this variable was estimated at $99 \%$. For a PR of 1.3, the estimated pow- 
er was 79\%. Still, with the observed PR (1.14), the power fell to $50 \%$. It can thus be concluded that the study had sufficient power to detect a medium or even small risk, but insufficient to detect a very small risk. As a whole, the above-mentioned limitations do not compromise the results.

The study showed that women have more morbidity than men, even after gender is adjusted to other factors that can affect outcome, such as age, marital status, unemployment, income, education, or social class. A very small difference was observed between the crude and adjusted $\mathrm{PR}$, meaning that there was no confounding.

The excess female morbidity found here is consistent with other studies in Brazil 8,16. Our study also showed that, as hypothesized previously, the effect of gender on morbidity was not equal for all morbidity measures used in this study. The effect was extremely high for having any symptom and for three or more symptoms, while for the other outcomes (potentially serious symptoms, self-rated health, and MPD), although women continued to show higher risks, the effect was smaller, less than twofold. The only exception to higher morbidity rates in women was "chronic health problems". Pinheiro et al. 8 detected a higher prevalence of this outcome among women, stratifying for age. In our study, the crude effect was $23 \%$ significantly higher in this group, but when adjusted to demographic and socioeconomic variables, the effect decreased $(\mathrm{PR}=1.14)$ and lost significance. The lack of higher risk for this outcome and the small effect for three of the other outcome variables may reflect (as previously proposed) that despite the consistent finding that females show more morbidity than males, some variation in the magnitude or even in the direction of the effect can be observed in specific conditions or for certain morbidity measures 17 .

The higher probability of women reporting more morbidity than men in this study can be explained by women's health-seeking behavior pattern. Health-seeking behavior refers to the succession of corrective actions that persons take to repair perceived ill health and begins with the perception of a health problem ${ }^{18}$. As mentioned above, women tend to perceive their health problems more intensely and to report them better than men, especially for minor problems 2 . This may explain the notoriously higher risk rates for reporting any symptom $(\mathrm{PR}=3.21)$ or three or more symptoms ( $\mathrm{PR}=4.22$ ). However, when the outcome is more serious (e.g., shortness of breath, bleeding, or chronic health problems), the difference is smaller or even disappears. That is, when there is greater apprehension over a serious illness, the predisposition to report morbidity is similar, and health-seeking behavior differs less between genders. Another explanation for the higher self-reported morbidity rates in women, particularly for minor physical illness, is that it may relate to higher rates of affective disorders, but some authors have rejected this argument 1 . Our study does not support this position either, because the PR for women with any symptom or three or more symptoms did not change when adjusted to MPD, showing that they were independent.

In conclusion, the current study identified differences between Brazilian women and men in self-reported morbidity, using more than one kind of self-reported morbidity, adjusting the model to known factors that can affect the outcome, such as age, marital status, and socioeconomic status. With the exception of chronic health problems, all morbidity measures were more common in women than in men. However, the degree to which women report more morbidity than men depends on the condition or kind of morbidity, which in turn reflects disparities in health perception and health-seeking behavior.

\section{Resumo}

O estudo teve como objetivo avaliar que diferenças ocorrem na morbidade referida entre homens e mulheres, utilizando seis medidas diferentes de morbidade. $O$ estudo de tipo transversal foi realizado no Município de Rio Grande, Sul do Brasil. Foram coletados dados demográficos, sócio-econômicos de uma amostra probabilística de 1.260 pessoas com 15 anos ou mais. Para fins estatísticos foi utilizada a regressão de Poisson. Após ajustar para variáveis de confusão, observou-se que as mulheres apresentavam maior risco de referir um sintoma ( $R P=3,21$; IC95\%: 2,71-3,83), de ter três ou mais sintomas ( $R P=4,22$; IC95\%: $2,97-5,98)$, de ter um sintoma potencialmente sério $(R P=1,75 ;$ IC95\%: 1,31-2,34), de apresentar uma percepção do estado de

saúde pobre ou regular ( $R P=1,78$; IC95\%: 1,37-2,32) e de sofrer de distúrbios psiquiátricos menores $(R P=$ 1,76; IC95\%: 1,31-2,37). O estudo aponta para a existência de diferenças entre os sexos na morbidade referida, mas com magnitudes diferentes conforme o tipo de medida de morbidade utilizada. Este excesso pode ser explicado pelas variações que ocorrem no comportamento na procura de cuidados em saúde (percepção elou informação de problemas de saúde) entre mulheres e homens.

Gênero; Aceitação pelo Paciente de Cuidados de Saúde; Morbidade 


\section{Contributors}

R. A. Mendoza-Sassi participated in the research design, data collection and analysis, and final draft of the article. J. U. Béria participated in the research project design, data analysis, manuscript review, and final draft.

\section{Acknowledgements}

Raúl A. Mendoza-Sassi was funded by the Coordenação de Aperfeiçoamento de Pessoal de Nível Superior (CAPES), Brasília, Brazil.

\section{References}

1. Popay J, Bartley M, Owen C. Gender inequalities in health: social position, affective disorders and minor physical morbidity. Soc Sci Med 1993; 36:21-32.

2. Verbrugge LM. Gender and health: an update on hypotheses and evidence. J Health Soc Behav 1985; 26:156-82.

3. Kunst A, Geurts J, van den Berg J. International variation in socioeconomic inequalities in selfreported health. J Epidemiol Community Health 1995; 49:117-23.

4. Patel V, Araya R, Lima M, Ludermir A, Todd C. Women, poverty and common mental disorders in four restructuring societies. Soc Sci Med 1999; 49:1461-71

5. Abreu DM, Rodrigues RN. Diferenciais de mortalidade entre as regiões metropolitanas de Belo Horizonte e Salvador, 1985-1995. Rev Saúde Pública 2000; 34:514-21.

6. Pinheiro R, Travassos C. Estudo da desigualdade na utilização de serviços de saúde por idosos em três regiões da cidade do Rio de Janeiro. Cad Saúde Pública 1999; 15:487-96.

7. Almeida C, Travassos C, Porto S, Labra M. Health sector reform in Brazil: a case study of inequity. Int J Health Serv 2000; 30:129-62.

8. Pinheiro R, Viacava F, Travassos C, Brito A. Gênero, morbidade, acesso e utilização de serviços de saúde no Brasil. Ciênc Saúde Coletiva 2002; 7:687-707.

9. Joung IM, van de Mheen H, Stronks K, van Poppel FW, Mackenbach JP. Differences in self-reported morbidity by marital status and by living arrangement. Int J Epidemiol 1994; 23:91-7.
10. Mendoza-Sassi R, Beria JU. Utilización de los servicios de salud: una revisión sistemática sobre los factores relacionados. Cad Saúde Pública 2001; 17:819-32.

11. Mossey JM, Shapiro E. Self-rated health: a predictor of mortality among the elderly. Am J Public Health 1982; 72:800-8.

12. Kaplan GA, Camacho T. Perceived health and mortality: a nine-year follow-up of the human population laboratory cohort. Am J Epidemiol 1983; 117:292-304.

13. Mari J, Williams P. A validity study of a psychiatric screening questionnaire (SRQ-20) in primary care in the city of Sao Paulo. Br J Psychiatry 1986; 148:23-6.

14. Associação Nacional de Empresas de Pesquisa. Economic classification criterion - Brazil. http:// www.abep.org/codigosguias/ABEP_CCEB.pdf (accessed on 10/Jul/1999).

15. Gove WR. Gender differences in mental and physical illness: the effects of fixed roles and nurturant roles. Soc Sci Med 1984; 19:77-91.

16. Coutinho E, Almeida Filho N, Mari J, Rodrigues L. Gender and minor psychiatric morbidity: results of a case-control study in a developing country. Int J Psychiatry Med 1999; 29:197-208.

17. MacIntyre S, Hunt K, Sweeting H. Gender differences in health: are things really as simple as they seem? Soc Sci Med 1996; 42:617-24.

18. Ward H, Mertens TE, Thomas C. Health-seeking behaviour and the control of sexually transmitted disease. Health Policy Plan 1996; 12:19-28.

Submitted on 08/Jun/2005

Final version resubmitted on 12/Mar/2006 Approved on 03/Apr/2006 